\title{
Prediction of postoperative inflammatory complications after esophageal cancer surgery based on early changes in the C- reactive protein level in patients who received perioperative steroid therapy and enhanced recovery after surgery care: a retrospective analysis
}

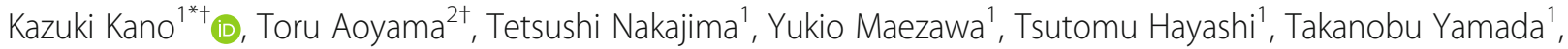
Tsutomu Sato' ${ }^{2}$ Takashi Oshima², Yasushi Rino², Munetaka Masuda², Haruhiko Cho', Takaki Yoshikawa' and Takashi Ogata ${ }^{*}$

\begin{abstract}
Background: Serum C-reactive protein (CRP) level can be an indicator of the early stage of infectious complications. However, its utility in advanced esophageal cancer patients who receive radical esophagectomy with two- or three-field lymph node dissection with perioperative steroid therapy and enhanced recovery after surgery (ERAS) care is unclear.

Methods: The present study retrospectively examined 117 consecutive esophageal cancer patients who received neoadjuvant chemotherapy followed by radical esophagectomy. All patients received perioperative steroid therapy and ERAS care. The utility of the CRP value in the early detection of serious infectious complications (SICS) was evaluated based on the area under the receiver operating characteristic curve (AUC). Univariate and multivariate logistic regression analyses were performed to identify the risk factors for SICs.

Results: SICs were observed in 20 patients (17.1\%). The CRP level on postoperative day (POD) 4 had superior diagnostic accuracy for SICS (AUC 0.778). The cut-off value for CRP was determined to be $4.0 \mathrm{mg} / \mathrm{dl}$. A multivariate analysis identified CRP $\geq 4.0 \mathrm{mg} / \mathrm{dl}$ on POD 4 (odds ratio, 18.600; 95\% confidence interval [Cl], 4.610-75.200) and three-field lymph node dissection (odds ratio, 7.950; 95\% Cl, 1.900-33.400) as independent predictive factors.

Conclusions: CRP value on POD 4 may be useful for predicting SICs in esophageal cancer patients who receive radical esophagectomy with perioperative steroid therapy and ERAS care. This result may encourage the performance of imaging studies to detect the focus and thereby lead to the early medical and/or surgical intervention to improve short-term outcomes.
\end{abstract}

Keywords: Esophageal cancer, Complication, Steroid therapy, C-reactive protein, Enhanced recovery after surgery care, Predictor

\footnotetext{
* Correspondence: kazuki05271981@yahoo.co.jp; ogatat@kcch.jp

${ }^{\dagger}$ Equal contributors

${ }^{1}$ Department of Gastrointestinal Surgery, Kanagawa Cancer Center, 2-3-2,

Nakao, Asahi-ku, Yokohama, Kanagawa 241-8515, Japan

Full list of author information is available at the end of the article
} 


\section{Background}

Preoperative chemo(radio)therapy and surgery have been established as the standard treatment for locally advanced esophageal cancer [1, 2]. Although recent advances in esophagectomy have decreased mortality, the morbidity remains high at 30\%-65\% [3, 4]. Among surgical morbidities, infectious complications (ICs) can be lethal if the initiation of effective treatment is delayed. However, the early clinical features of ICs are nonspecific and difficult to distinguish from normal postoperative inflammatory responses associated with surgical invasion [5]. Therefore, ICs are often diagnosed after patients develop apparent clinical symptoms. Indeed, the median time to the diagnosis ICs was reportedly up to 12 days after surgery [6]. To improve the short-term outcomes, approaches other than symptom observation must be adopted for the early detection of ICs.

Several studies have reported the utility of serum Creactive protein $(\mathrm{CRP})$ in predicting ICs before clinical signs and symptoms develop [7, 8]. However, previous studies have included patients with esophagogastric junctional adenocarcinoma, and some were performed in Western populations. The Eastern surgical procedure, which was defined as radical esophagectomy with extended lymph node dissection, the cervical and upper mediastinal as well as middle-lower mediastinal and abdominal lymph node dissection [9, 10], for esophageal squamous cell carcinoma located in the thoracic esophagus is a highly invasive surgery, that is completely different from the Ivor-Lewis procedure for esophageal adenocarcinoma located in the distal esophagus [11]. Furthermore, perioperative managements, such as steroid therapy and enhanced recovery after surgery (ERAS) care, that have been introduced in many hospitals to reduce the morbidity and mortality, were recently reported to reduce the postoperative serum CRP levels [12-15], making ICs more difficult to diagnose in the early period. Thus, the findings from previous reports on the utility of CRP levels in the early prediction of ICs cannot be generalized.

The aim of this study was to assess whether early changes in the serum CRP can be used to predict ICs in advanced esophageal cancer patients who received esophagectomy and two- or three-field lymph node dissection with perioperative steroid therapy and ERAS care.

\section{Methods}

\section{Patient data}

The patients were selected from the medical records of consecutive patients who underwent esophagectomy for esophageal cancer at Kanagawa Cancer Center from January 2011 to September 2015. The patients met the following inclusion criteria: (1) histologically proven primary esophageal squamous cell carcinoma located at thoracic esophagus, (2) clinical stage I to III (excluding T4) disease as evaluated using the 7th edition of the tumor-node-metastasis classification established by the Union for International Cancer Control [16], and (3) neoadjuvant chemotherapy followed by curative resection with radical lymph node dissection.

\section{Preoperative chemotherapy}

The patients received two courses of cisplatin plus 5 -fluorouracil. Cisplatin was administered at a dose of $80 \mathrm{mg} / \mathrm{m}^{2}$ by intravenous drip infusion on day 1 , and 5fluorouracil was administered at a dose of $800 \mathrm{mg} / \mathrm{m}^{2}$ by continuous infusion on days 1-5 [1].

\section{Surgical procedure}

Surgical resection was generally performed 4-6 weeks after the completion of chemotherapy. Our standard procedures consisted of open subtotal esophagectomy via right anterolateral thoracotomy, reconstruction with a gastric tube through the posterior mediastinal route or retrosternal route, and anastomosis in the cervical incision. In principle, two-field lymph node dissection is indicated when tumors are located at the middle thoracic to lower thoracic esophagus, while three-field is applied for upper thoracic tumors. Multiple drains were placed; one to the posterior side of the thoracic cavity and the others on either side of the neck. A feeding tube was routinely placed at the stomach or duodenum.

\section{Perioperative care}

All of the patients received perioperative management by the clinical path based on the ERAS program, which routinely included antibiotic prophylaxis and steroid therapy. Cefazolin ( $1 \mathrm{~g}$ ) was administered $30 \mathrm{~min}$ before surgical incision and then again every 3 hours during surgery and at $2 \mathrm{~g}$ on postoperative day (POD) 1. Methylprednisolone was administered at a dose of $500 \mathrm{mg}$ on the day of surgery, $250 \mathrm{mg}$ on POD 1, and $125 \mathrm{mg}$ on POD $2[13,14]$. Our ERAS program satisfied the 15 items proposed by Fearon et al. [17]. Briefly, the patients were allowed to eat $30 \%$ rice porridge until midnight the day before the surgery and were required to drink the contents of two 500-ml plastic bottles containing oral rehydration solution by $3 \mathrm{~h}$ before surgery. Intraoperatively, we conducted epidural anesthesia with morphine for pain control during surgery. Previous study showed the use of the epidural anesthesia with morphine has clinical benefits such as, a selective analgesia with no motor or sympathetic blockade and a long analgesia at low use of rescue medication $[18,19]$. However, the use of the epidural anesthesia with morphine could cause delayed respiratory depression and apnea as late as 12 hours after administration [20]. Therefore, the patients 
remained on ventilation for 12 hours after surgery. After 12 hours, we carefully observe respiratory condition and extubate. Ambulation and enteral nutrition was started on POD 1. Oral intake was initiated on POD 6, beginning with water and gelatinous foods. The patients began to eat solid food on POD 9, starting with rice gruel and soft food and progressing in three steps to regular food intake.
Definition of surgical complications and measurement of CRP All data were retrospectively retrieved from the patients' records. ICs were defined as complications of anastomotic leakage, pneumonia, abdominal abscess, and/or pyothorax according to the Clavien-Dindo classification [21] occurring during hospitalization within 30 days after surgery. Of these, ICs $\geq$ grade IIIa were defined as serious ICs (SICs). The complications were assessed

Table 1 A comparison of patients' characteristics and surgical findings between the patients with and without postoperative serious infectious complications

\begin{tabular}{|c|c|c|c|c|}
\hline Variables & $\begin{array}{l}\text { All Patients } \\
(n=117)\end{array}$ & $\begin{array}{l}\text { SICs group } \\
(n=20)\end{array}$ & $\begin{array}{l}\text { NSICs group } \\
(n=97)\end{array}$ & $p$ value \\
\hline Age (years), median (range) & $66(48-77)$ & $68(50-77)$ & $66(48-77)$ & 0.289 \\
\hline Gender & & & & 0.356 \\
\hline Male & $94(80.3 \%)$ & $18(90.0 \%)$ & $76(78.4 \%)$ & \\
\hline Female & $23(19.7 \%)$ & $2(10.0 \%)$ & $21(21.6 \%)$ & \\
\hline Preoperative body mass index (kg/m2), median (range) & $21.1(15.4-28.9)$ & $21.8(17.8-26.7)$ & $20.5(15.4-28.9)$ & 0.205 \\
\hline Preoperative serum albumin (g/dl), median (range) & $4.1(2.3-6.4)$ & $4.1(3.2-4.4)$ & $4.1(2.3-6.4)$ & 0.202 \\
\hline ASA-PS & & & & 0.779 \\
\hline 1 & $17(14.5 \%)$ & $2(10.0 \%)$ & $15(15.5 \%)$ & \\
\hline 2 & $99(84.6 \%)$ & $18(90.0 \%)$ & $81(83.5 \%)$ & \\
\hline 3 & $1(0.9 \%)$ & $0(0.0 \%)$ & $1(1.0 \%)$ & \\
\hline Main tumor location & & & & 0.091 \\
\hline Upper thoracic esophagus & $16(13.7 \%)$ & $6(30.0 \%)$ & $10(10.3 \%)$ & \\
\hline Middle thoracic esophagus & $61(52.1 \%)$ & $9(45.0 \%)$ & $52(53.6 \%)$ & \\
\hline Lower thoracic esophagus & $40(34.2 \%)$ & $5(25.0 \%)$ & $35(36.1 \%)$ & \\
\hline UICC clinical T factor before neoadjuvant chemotherapy & & & & 0.235 \\
\hline cT1 & $2(1.7 \%)$ & $1(5.0 \%)$ & $1(1.0 \%)$ & \\
\hline cT2 & $39(33.3 \%)$ & $8(40.0 \%)$ & $31(32.0 \%)$ & \\
\hline cT3 & $76(65.0 \%)$ & $11(55.0 \%)$ & $65(67.0 \%)$ & \\
\hline UICC clinical N factor before neoadjuvant chemotherapy & & & & 0.841 \\
\hline cNO & $50(42.7 \%)$ & $8(40.0 \%)$ & $42(43.3 \%)$ & \\
\hline $\mathrm{cN1}$ & $66(56.4 \%)$ & $12(60.0 \%)$ & $54(55.7 \%)$ & \\
\hline cN2 & $1(0.9 \%)$ & $0(0.0 \%)$ & $1(1.0 \%)$ & \\
\hline UICC clinical stage before neoadjuvant chemotherapy & & & & 0.090 \\
\hline $\mathrm{IB}$ & $23(19.7 \%)$ & $7(35.0 \%)$ & $16(16.5 \%)$ & \\
\hline$\| \mathrm{A}$ & $27(23.1 \%)$ & $1(5.0 \%)$ & $26(26.8 \%)$ & \\
\hline$\| B$ & $18(15.4 \%)$ & $2(10.0 \%)$ & $16(16.5 \%)$ & \\
\hline IIIA & $48(41.0 \%)$ & $10(50.0 \%)$ & $38(39.2 \%)$ & \\
\hline$\| I B$ & $1(0.9 \%)$ & $0(0.0 \%)$ & $1(1.0 \%)$ & \\
\hline Lymph node dissection & & & & 0.023 \\
\hline Two-field & $95(81.2 \%)$ & $12(60.0 \%)$ & $83(85.6 \%)$ & \\
\hline Three-field & $22(18.8 \%)$ & $8(40.0 \%)$ & $14(14.4 \%)$ & \\
\hline Operation time (min), median (range) & $400(298-593)$ & $430.0(345-593)$ & $\begin{array}{l}395 \\
(298-593)\end{array}$ & 0.111 \\
\hline Intraoperative blood loss (ml), median (range) & $420(110-3000)$ & $682.5(185-3000)$ & $400(110-2350)$ & 0.018 \\
\hline
\end{tabular}

SICS Serious infectious complications, ASA-PS American Society of Anesthesiologists Physical Status, UICC Union for International Cancer Control 
based on the clinical symptoms, blood tests, and X-ray imaging at POD 1, 2, 4, 6, 8, and thereafter. If ICs were suspected, precise examinations, such as computed tomography, esophagography, and esophagoduodenoscopy, were performed.

\section{Statistical analyses}

A two-sided $P$ value $<0.05$ was considered significant. Continuous data are presented as the median with the range. The Mann-Whitney U test and Fisher's exact test were employed to evaluate the differences in continuous and categorical variables, respectively. The patients were classified as those with SICs (SICs group) and those without SICs (NSICs group). The diagnostic accuracy was determined based on the area under the receiver operating characteristic (ROC) curve (AUC) [22]. The optimal cut-off value of CRP was determined by maximizing Youden's index. The optimum value of CRP was then determined based on the AUC and the earliest prediction of SICs. The predictive value of CRP, categorized as high or low by the cut-off value at the optimum point, was examined using univariate and multivariate logistic regression analyses. All statistical analyses were performed with EZR (Saitama Medical Center, Jichi Medical University, Saitama, Japan), which is a graphical user interface for R (The R Foundation for Statistical Computing, Vienna, Australia). More precisely, it is a modified version of $\mathrm{R}$ commander designed to add statistical functions frequently used in biostatistics [23].

\section{Results}

\section{Patient characteristics}

A total of 208 patients underwent esophagectomy for esophageal squamous cell carcinoma between January 2011 and September 2015. Excluding 3 patients with no survival information available, 7 patients who were not diagnosed with squamous cell carcinoma, 74 patients who did not receive neoadjuvant chemotherapy, and 7 patients who did not receive curative resection, one hundred and seventeen of these patients were eligible for the present study (56.3\%). The patient characteristics are summarized in Table 1. The SICs group received three-field lymph node dissection more frequently $(p=0.023)$ and had greater blood loss $(p=0.018)$ than the NSICs group.

\section{Surgical morbidity and mortality}

SICs were observed in 20 patients (17.1\%). The details of the complications and duration from surgery to their diagnosis are shown in Table 2. The median duration until the diagnosis of any SICs was 7 days (range: 4-14).

\section{Postoperative CRP level with SICs}

The changes in the CRP level after esophagectomy are shown in Fig. 1. The preoperative CRP level was not
Table 2 Details of serious infectious complications and duration from surgery to the diagnosis of those complications

\begin{tabular}{|c|c|c|c|c|c|c|c|}
\hline \multirow[b]{2}{*}{ Complications } & \multicolumn{5}{|c|}{$\begin{array}{l}\text { Grade according } \\
\text { to Clavein-Dindo } \\
\text { classification }\end{array}$} & \multirow[t]{2}{*}{ Total (\%) } & \multirow[t]{2}{*}{$\begin{array}{l}\text { Duration to diagnose } \\
\text { SICs, median (range) }\end{array}$} \\
\hline & $3 a$ & $3 b$ & $4 a$ & $4 b$ & 5 & & \\
\hline $\begin{array}{l}\text { Anastomotic } \\
\text { leakage }\end{array}$ & 16 & 0 & 0 & 0 & 0 & 16 (13.7\%) & $6(4-10)$ \\
\hline $\begin{array}{l}\text { Abdominal } \\
\text { abscess }\end{array}$ & 0 & 1 & 0 & 0 & 0 & $1(0.9 \%)$ & $7(7)$ \\
\hline Pneumonia & 1 & 0 & 1 & 0 & 0 & $2(1.7 \%)$ & $6(5-7)$ \\
\hline Pyothorax & 5 & 0 & 0 & 0 & 0 & $5(4.3 \%)$ & $10(6-14)$ \\
\hline Total & 22 & 1 & 1 & 0 & 0 & 24 (20.5\%) & 7 (4-14) \\
\hline
\end{tabular}

There is some overlapping.

SICS Serious infectious complications, POD Postoperative day

markedly different between the SICs and NSICs groups. After surgery, the CRP level reached its first peak on POD 1 and 2, with no significant differences between the two groups, and then decreased to its lowest value on POD 4. However, the subsequent CRP levels on POD 4,6 , and 8 were significantly higher in the SICs group than in the NSICs group. The AUC for prediction by CRP was 0.778 (95\% CI, 0.673-0.884) on POD 4 (Fig. 2a), 0.875 (95\% CI, 0.799-0.952) on POD 6 (Fig. 2b), and 0.883 (95\% CI, 0.813-0.953) on POD 8 (Fig. 2c). Considering the AUC and earliest prediction of SICs, the optimum cut-off value of CRP was determined to be 4.0 $\mathrm{mg} / \mathrm{dl}$ on POD 4. By this cut-off, 40 patients had high CRP with median of $6.95 \mathrm{mg} / \mathrm{dl}$ (range: 4.01-28.51), while 77 patients had CRP with median of $1.50 \mathrm{mg} / \mathrm{dl}$ (range: 0.13-3.99). Among 40 patients with high CRP

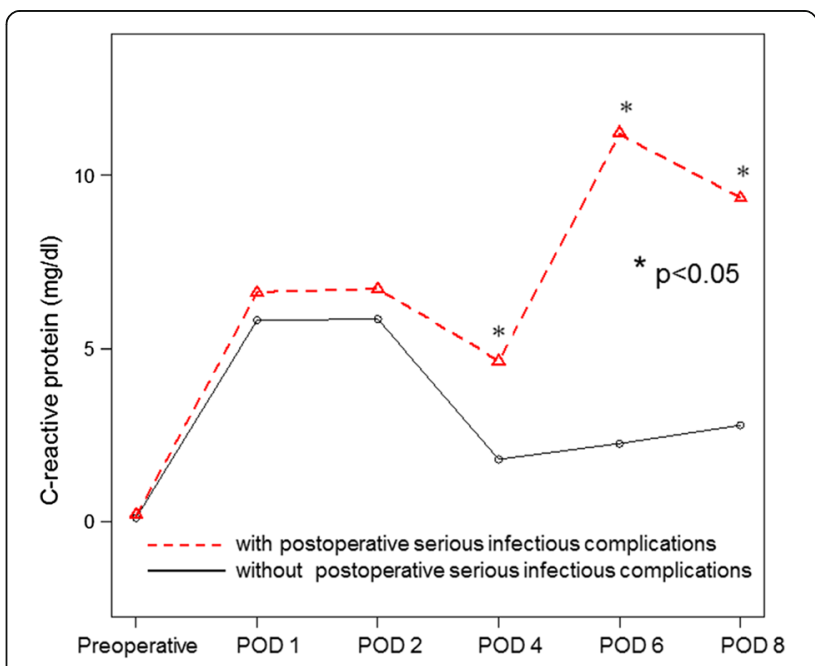

Fig. 1 Changes in the C-reactive protein (CRP) levels between patients with and without serious infectious complications (SICS). The CRP levels were significantly different on postoperative days 4,6 , and 8 . The optimum CRP value for the prediction of SICs was determined to be that measured on POD 4 

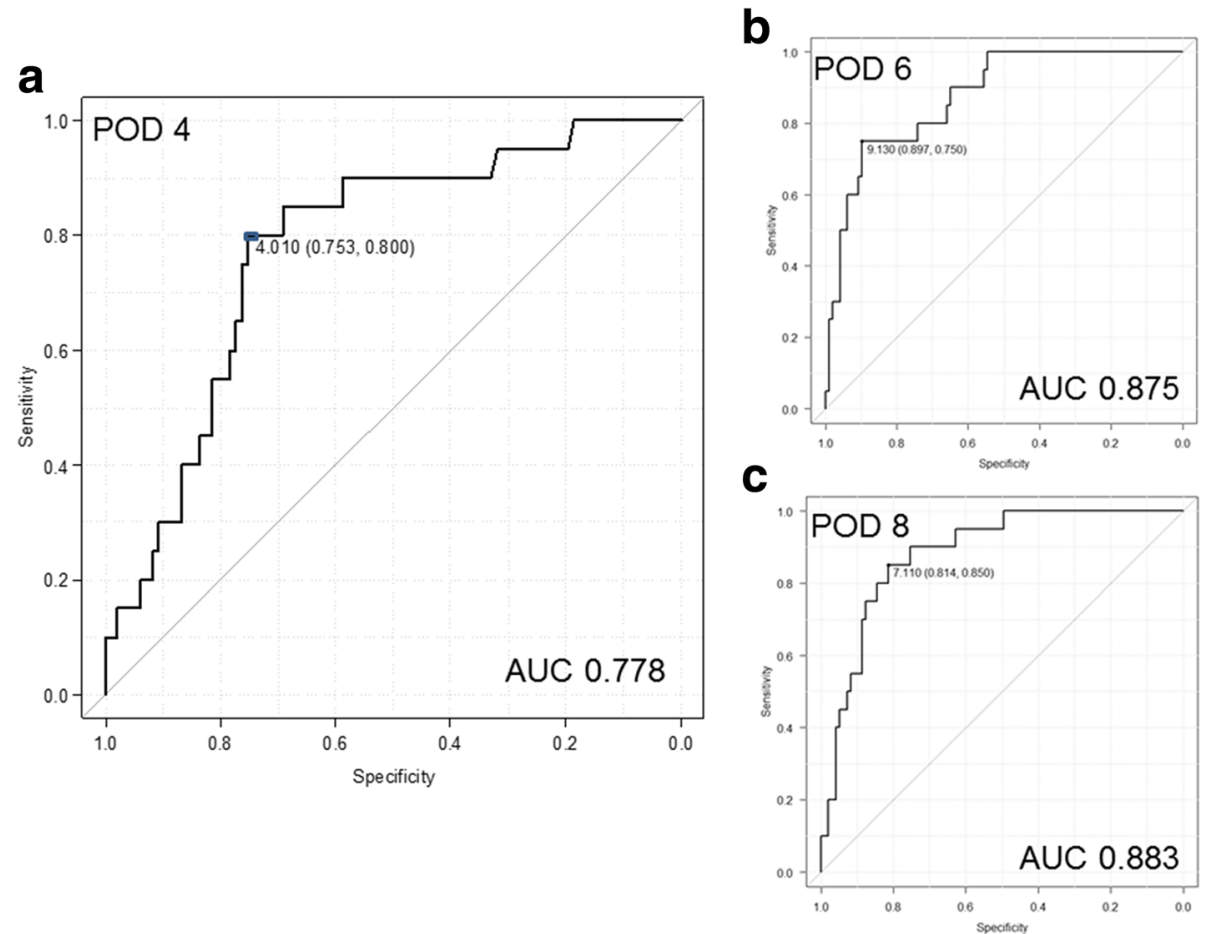

Fig. 2 Diagnostic accuracy was determined based on the area under the receiver operating characteristic (ROC) Curve (AUC) (CRP on POD 4, 6, and 8) for predicting SICs. The AUC for prediction by CRP was 0.778 ( $95 \% \mathrm{Cl}, 0.673-0.884)$ on POD 4 (a), 0.875 (95\% Cl, 0.799-0.952) on POD 6 (b), and $0.883(95 \% \mathrm{Cl}, 0.813-0.953)$ on POD 8 (c)

levels, 16 developed SICs; anastomotic leakage in 12 patients, pneumonia in 2 , abdominal abscess in 1 , and pyothorax in 3 . The sensitivity and specificity were $80.0 \%$ and $75.3 \%$, respectively, and the negative and positive predictive values (NPV and PPV) were $94.8 \%$ and $40.1 \%$, respectively.

\section{Risk factors for SICs}

Table 3 shows the results of univariate and multivariate analyses (Table 3). Among these, CRP $\geq 4.0 \mathrm{mg} / \mathrm{dl}$ on POD 4 (odds ratio, 18.600; 95\% CI, 4.610-75.200) and three-field lymph node dissection (odds ratio, 7.950; 95\% CI, 1.900-33.400) were identified as significant independent predictive factors for SICs.

\section{Discussion}

The present study examined whether CRP levels can predict SICs in 117 advanced esophageal squamous cell carcinoma patients who received neoadjuvant chemotherapy followed by curative resection with perioperative steroid therapy and ERAS care. This study found that a CRP level exceeding $4.0 \mathrm{mg} / \mathrm{dl}$ on POD 4 was useful for predicting SICs in esophageal squamous cell carcinoma patients who received radical esophagectomy with perioperative steroid therapy and ERAS care. A high CRP level on POD 4 may encourage the performance of imaging studies to detect the focus and thereby lead to early medical and/or surgical intervention.

The cut-off CRP value was $4.0 \mathrm{mg} / \mathrm{dl}$ on POD 4 in the present study. Compared with previous studies examining the utility of CRP in predicting SICs, our surgical approach was highly invasive, but the operation time and blood loss were similar $[24,25]$. However, the cut-off CRP value was much lower than in previous studies, ranging from 11.1 to $18.0 \mathrm{mg} / \mathrm{dl}$ on POD 3 or $4[7,8$, 26]. This low cut-off CRP value may be explained by the use of steroid therapy and ERAS in our study, which helped reduce the surgical stress-induced inflammatory responses [12-15]. Several studies reported that the postoperative CRP levels were decreased to nearly half in patients who underwent esophagectomy and received perioperative steroid therapy [13, 14]. Furthermore, Chen et al. found that the postoperative CRP levels on POD 1,3 , and 7 were significantly lower in patients who received perioperative care with fast track surgery than in others [15].

Although the cut-off CRP value in the present study was low, the sensitivity and specificity were around 70\%$80 \%$, which was concordant with the values in previous studies [7, 8, 26, 27]. Furthermore, the high NPV of $94.8 \%$ in the present study suggested that SICs can be ruled out when the CRP is less than $4.0 \mathrm{mg} / \mathrm{dl}$ on POD 4 [28]. However, the PPV of $40.1 \%$ might be too low to 
Table 3 Predictive factors for serious infectious complications

\begin{tabular}{|c|c|c|c|c|c|c|c|}
\hline \multirow[t]{2}{*}{ Factors } & \multirow[t]{2}{*}{ Number of patients (\%) } & \multicolumn{3}{|c|}{ Univariate } & \multicolumn{3}{|c|}{ Multivariate } \\
\hline & & OR & $95 \% \mathrm{Cl}$ & $p$ value & $\mathrm{OR}$ & $95 \% \mathrm{Cl}$ & $p$ value \\
\hline \multicolumn{4}{|l|}{ Age (years) } & 0.271 & & & \\
\hline$\leq 66$ & $60(51.3 \%)$ & 1.000 & & & & & \\
\hline$>66$ & $57(48.7 \%)$ & 1.730 & $0.651-4.620$ & & & & \\
\hline \multicolumn{4}{|l|}{ Gender } & 0.246 & & & \\
\hline Female & $23(19.7 \%)$ & 1.000 & & & & & \\
\hline Male & $94(80.3 \%)$ & 2.490 & $0.534-11.600$ & & & & \\
\hline \multicolumn{4}{|c|}{ Preoperative body mass index (kg/m2) } & 0.183 & & & \\
\hline$\leq 21$ & $57(48.7 \%)$ & 1.000 & & & & & \\
\hline$>21$ & $60(51.3 \%)$ & 1.980 & $0.726-5.380$ & & & & \\
\hline \multicolumn{4}{|l|}{ ASA-PS } & 0.531 & & & \\
\hline 1 & $17(14.5 \%)$ & 1.000 & & & & & \\
\hline $2 / 3$ & $100(85.5 \%)$ & 1.650 & $0.346-7.840$ & & & & \\
\hline \multicolumn{4}{|c|}{ Preoperative serum albumin (g/dl) } & 0.900 & & & \\
\hline$\geq 4.1$ & $60(51.3 \%)$ & 1.000 & & & & & \\
\hline$<4.1$ & $57(48.7 \%)$ & 1.060 & $0.406-2.790$ & & & & \\
\hline \multicolumn{4}{|c|}{ UICC clinical T factor before neoadjuvant chemotherapy } & 0.308 & & & \\
\hline $\mathrm{CT} 1-2$ & $41(35.0 \%)$ & 1.000 & & & & & \\
\hline cT3 & $76(65.0 \%)$ & 0.602 & $0.226-1.600$ & & & & \\
\hline \multicolumn{4}{|c|}{ UICC clinical N factor before neoadjuvant chemotherapy } & 0.786 & & & \\
\hline cNO & $50(42.7 \%)$ & 1.000 & & & & & \\
\hline $\mathrm{cN} 1-2$ & $67(57.3 \%)$ & 1.150 & $0.430-3.050$ & & & & \\
\hline \multicolumn{4}{|c|}{ Lymph node dissection } & 0.011 & & & 0.005 \\
\hline Two-field & $95(81.2 \%)$ & 1.000 & & & 1.000 & & \\
\hline Three-field & $22(18.8 \%)$ & 3.950 & $1.370-11.400$ & & 7.950 & $1.900-33.400$ & \\
\hline \multicolumn{4}{|c|}{ Operation time (min) } & 0.135 & & & \\
\hline$\leq 400$ & $59(50.4 \%)$ & 1.000 & & & & & \\
\hline$>400$ & $58(49.6 \%)$ & 2.150 & $0.788-5.840$ & & & & \\
\hline \multicolumn{4}{|c|}{ Intraoperative blood loss (ml) } & 0.237 & & & \\
\hline$\leq 420$ & $61(52.1 \%)$ & 1.000 & & & & & \\
\hline$>420$ & $56(47.9 \%)$ & 1.810 & $0.678-4.810$ & & & & \\
\hline \multicolumn{4}{|c|}{ CRP on POD4 (mg/dl) } & $<0.001$ & & & $<0.001$ \\
\hline$\leq 4.0$ & 77 (65.8\%) & 1.000 & & & 1.000 & & \\
\hline$>4.0$ & $40(34.5 \%)$ & 12.200 & $3.710-39.900$ & & 18.600 & $4.610-75.200$ & \\
\hline
\end{tabular}

SICS Serious infectious complications, CI Confidence interval, OR odds ratio, ASA-PS American Society of Anesthesiologists Physical Status, CRP C-reactive protein; $P O D$, postoperative day, UICC Union for International Cancer Control

support the accurate diagnosis of SICs based on CRP values. Therefore, patients with CRP levels $\geq 4.0 \mathrm{mg} /$ $\mathrm{dl}$ on POD 4 must be screened for SICs by further diagnostic measures, like X-rays, upper gastrointestinal series, or computed tomography. CRP measurement on POD 4 is nonspecific, but it is nevertheless helpful since it encourages the performance of further studies to detect the focus [27].

The earliest point for the successful prediction by the CRP level was POD 4 in the present study, which has clinical impact as physicians can initiate early goaldirected therapy, thereby improving patients' short-term outcome [5, 24]. Generally, the half-life of CRP is $19 \mathrm{~h}$ [29]. Several investigators have reported that the CRP level peaked on POD 2 before normalizing on POD 3 following various types of surgery [7, 28, 29]. Because this study did not measure the CRP level on POD 3, it remains unclear whether SICs could be predicted on POD 3. However, the CRP level on POD 6 and 8 had high diagnostic accuracy in the present study, possibly 
suggesting that CRP increased with the progression of SICs; however, no effective treatment was introduced, possibly due to the lack of any clinical sign of SICs. In other words, SICs may actually start on POD 4 rather than simply being detected on that day. This hypothesis is supported by the findings from previous studies [27, 30], as Deitmar et al. showed that elevated CRP levels precede the development of SICs by 3 days [30].

Our results demonstrated that three-field lymph node dissection had more complications than two-field. According to the previous reports, it is controversial whether the addition of lateral neck dissection may lead to SICs [9]. Recent meta-analysis showed that three-field lymph node dissection had more complications than two-field [31]. In this study, three-field lymph node dissection was applied for upper thoracic tumors, which might have resulted in SICs. Although the difference between two- or three-field lymph node dissection is just whether lateral neck dissection is added or not, technical difficulties in surgery for the proximal esophagus might increase SICs [32]. In fact, postoperative complications had been reported in as high as 61.5 to $71.4 \%$ of patients with the upper thoracic esophageal cancer [33].

The present study is associated with several potential limitations. First, it was a retrospective single-center study with a small sample size. Second, there is no standard type, period, or dose of perioperative steroid therapy. The perioperative ERAS program also differs by hospital. Thus, the cut-off CRP value likely differs depending on the perioperative management regimen adopted by a given hospital. Third, the present study only investigated the outcomes following open subtotal esophagectomy via right anterolateral thoracotomy. Recently, minimally invasive surgery has been introduced [34]. Because the invasiveness of surgery is different, the cut-off CRP value may also be different with minimally invasive surgery. To confirm the present results, prospective study is necessary.

\section{Conclusions}

A high CRP level $\geq 4.0 \mathrm{mg} / \mathrm{dl}$ on POD 4 may predict SICs in esophageal cancer patients who received neoadjuvant chemotherapy followed by curative resection with perioperative steroid therapy and ERAS care. This result may encourage the performance of imaging studies to detect the focus and thus lead to early medical and/or surgical intervention, thereby helping to improve the short-term outcome.

\footnotetext{
Abbreviations

AUC: Area under the receiver operating characteristic curve; $\mathrm{Cl}$ : Confidence interval; CRP: C-reactive protein; ERAS: Enhanced recovery after surgery; IRB: Institutional Review Board; NPV: Negative predictive value; POD: Postoperative day; PPV: Positive predictive value; ROC: Receiver operating characteristic; SICs: Serious infectious complications
}

\section{Acknowledgments}

The authors express their sincere gratitude to Ms. Natsumi Sato and Ms. Rika Takahashi for their excellent data management in this study.

Funding

No funding.

\section{Availability of data and materials}

The datasets analysed during the current study are available from the corresponding author on reasonable request.

\section{Authors' contributions}

KK, TA, TY and TO made substantial contributions to conception and design. KK, TA, TN, YM, TH, TY, TS, HC, TY and TO made substantial contributions to acquisition of data, or analysis and interpretation of data. KK, TA, TH, TY, TS, HC, TY and TO have been involved in drafting the manuscript or revising it critically for important intellectual content. TO, YR, and MM have given final approval of the version to be published. Each author should have participated sufficiently in the work to take public responsibility for appropriate portions of the content; and agreed to be accountable for all aspects of the work in ensuring that questions related to the accuracy or integrity of any part of the work are appropriately investigated and resolved. All authors read and approved the final manuscript.

\section{Ethics approval and consent to participate}

This retrospective study was approved by the Institutional Review Board (IRB) of the Kanagawa Cancer Center in 2015 (2015.epidemiologic study-31). Based on this IRB-approval, we retrospectively collected clinical data of patients who received surgery during Jan 2011 and Sep 2015. Because the study was retrospective study without any investigational intervention, the study-specific informed consent was not obtained from each patient. Instead, we obtained the comprehensive written informed consent for retrospective study from all patients since 2010, including the patients who entered into the present study. This policy was in compliance with Helsinki Declaration of 1975, as revised in 1983 and with Japanese ethical guideline for clinical studies 2014. Recently, revised Japanese ethical guideline for clinical studies was applied since June 2017 and informed consent was principally mandatory as long as no difficulty for acquisition of consent even for retrospective study, however, the data collection of the present study had been finished until Jan 2016.

\section{Consent for publication}

Not applicable.

\section{Competing interests}

The authors declare that they have no competing interests.

\section{Publisher's Note}

Springer Nature remains neutral with regard to jurisdictional claims in published maps and institutional affiliations.

\section{Author details}

'Department of Gastrointestinal Surgery, Kanagawa Cancer Center, 2-3-2, Nakao, Asahi-ku, Yokohama, Kanagawa 241-8515, Japan. ${ }^{2}$ Department of Surgery, Yokohama City University, 3-9, Fukuura, Kanazawa-ku, Yokohama, Kanagawa 236-0004, Japan.

Received: 18 July 2017 Accepted: 23 November 2017 Published online: 04 December 2017

\section{References}

1. Ando N, Kato H, Igaki H, Shinoda M, Ozawa S, Shimizu H, et al. A randomized trial comparing postoperative adjuvant chemotherapy with cisplatin and 5-fluorouracil versus preoperative chemotherapy for localized advanced squamous cell carcinoma of the thoracic esophagus (JCOG9907). Ann Surg Oncol. 2012;19:68-74.

2. van Hagen P, Hulshof MC, van Lanschot JJ, Steyerberg EW, van Berge Henegouwen MI, Wijnhoven BP, et al. Preoperative chemoradiotherapy for esophageal or junctional cancer. N Engl J Med. 2012;366:2074-84.

3. Zafirellis KD, Fountoulakis A, Dolan K, Dexter SP, Martin IG, Sue-Ling HM Evaluation of POSSUM in patients with oesophageal cancer undergoing resection. Br J Surg. 2002;89:1150-5. 
4. Biere SS, Maas KW, Cuesta MA, van der Peet DL. Cervical or thoracic anastomosis after esophagectomy for cancer: a systematic review and meta-analysis. Dig Surg. 2011;28:29-35.

5. Hyman N, Manchester TL, Osler T, Burns B, Cataldo PA. Anastomotic leaks after intestinal anastomosis: it's later than you think. Ann Surg. 2007;245:254-8.

6. Vonlanthen R, Slankamenac K, Breitenstein S, Puhan MA, Muller MK Hahnloser D, et al. The impact of complications on costs of major surgical procedures: a cost analysis of 1200 patients. Ann Surg. 2011;254:907-13.

7. Dutta S, Fullarton GM, Forshaw MJ, Horgan PG, McMillan DC. Persistent elevation of C-reactive protein following esophagogastric cancer resection as a predictor of postoperative surgical site infectious complications. World J Surg. 2011;35:1017-25.

8. Warschkow R, Tarantino I, Ukegjini K, Beutner U, Müller SA, Schmied BM, et al. Diagnostic study and meta-analysis of $C$-reactive protein as a predictor of postoperative inflammatory complications after gastroesophageal cancer surgery. Langenbecks Arch Surg. 2012;397:727-36.

9. Igaki H, Tachimori Y, Kato H. Improved survival for patients with upper and/ or middle mediastinal lymph node metastasis of squamous cell carcinoma of the lower thoracic esophagus treated with 3-field dissection. Ann Surg. 2004;239:483-90

10. Ye T, Sun $Y$, Zhang $Y$, Zhang $Y$, Chen $H$. Three-field or two-field resection for thoracic esophageal cancer: a meta-analysis. Ann Thorac Surg. 2013;96:1933-41.

11. Hiranyatheb P, Osugi H. Radical lymphadenectomy in esophageal cancer: from the past to the present. Dis Esophagus. 2015;28:68-77.

12. Zhao G, Cao S, Cui J. Fast-track surgery improves postoperative clinical recovery and reduces postoperative insulin resistance after esophagectomy for esophageal cancer. Support Care Cancer. 2014;22:351-8.

13. Sato N, Koeda K, Ikeda K, Kimura Y, Aoki K, Iwaya T, et al. Randomized study of the benefits of preoperative corticosteroid administration on the postoperative morbidity and cytokine response in patients undergoing surgery for esophageal cancer. Ann Surg. 2002;236:184-90.

14. Shimada H, Ochiai T, Okazumi S, Matsubara H, Nabeya Y, Miyazawa Y, et al. Clinical benefits of steroid therapy on surgical stress in patients with esophageal cancer. Surgery. 2000;128:791-8.

15. Chen L, Sun L, Lang Y, Wu J, Yao L, Ning J, et al. Fast-track surgery improves postoperative clinical recovery and cellular and humoral immunity after esophagectomy for esophageal cancer. BMC Cancer. 2016;16:449.

16. Sobin LH, Gospodarowicz MK, Wittekind C. TNM classification of malignant tumors. 7. Oxford: Wiley-Blackwell; 2010.

17. Fearon KC, Ljungqvist $O$, Von Meyenfeldt $M$, Revhaug A, Dejong $\mathrm{CH}$, Lassen $K$, et al. Enhanced recovery after surgery: a consensus review of clinical care for patients undergoing colonic resection. Clin Nutr. 2005;24:466-77.

18. Gambling D, Hughes T, Martin G, Horton W, Manvelian G. A comparison of Depodur, a novel, single-dose extended-release epidural morphine, with standard epidural morphine for pain relief after lower abdominal surgery. Anesth Analg. 2005;100:1065-74.

19. Wheatley RG, Schug SA, Watson D. Safety and efficacy of postoperative epidural analgesia. Br J Anaesth. 2001;87:47-61.

20. Weingarten TN, Warner LL, Sprung J. Timing of postoperative respiratory emergencies: when do they really occur? Curr Opin Anaesthesiol. 2017;30:156-62.

21. Dindo D, Demartines N, Clavien PA. Classification of surgical complications: a new proposal with evaluation in a cohort of 6336 patients and results of a survey. Ann Surg. 2004;240:205-13.

22. Soreide K. Receiver-operating characteristic curve analysis in diagnostic prognostic and predictive biomarker research. J Clin Pathol. 2009;62:1-5.

23. Kanda Y. Investigation of the freely-available easy-to-use software "EZR" (Easy R) for medical statistics. Bone Marrow Transplant. 2013;48:452-8.

24. Yamashita K, Makino T, Miyata H, Miyazaki Y, Takahashi T, Kurokawa Y, et al. Postoperative infectious complications are associated with adverse oncologic outcomes in esophageal cancer patients undergoing preoperative chemotherapy. Ann Surg Oncol. 2016;23:2106-14.

25. Hirahara N, Matsubara T, Hayashi H, Takai K, Fujii Y, Tajima Y. Impact of inflammation-based prognostic score on survival after curative thoracoscopic esophagectomy for esophageal cancer. Eur J Surg Oncol. 2015;41:1308-15.

26. Miki Y, Toyokawa T, Kubo N, Tamura T, Sakurai K, Tanaka H, et al. C-reactive protein indicates early stage of postoperative infectious complications in patients following minimally invasive esophagectomy. World J Surg. 2017;41:796-803

27. Shishido Y, Fujitani K, Yamamoto K, Hirao M, Tsujinaka T, Sekimoto M. Creactive protein on postoperative day 3 as a predictor of infectious complications following gastric cancer resection. Gastric Cancer. 2016;19:293-301.

28. Singh PP, Zeng IS, Srinivasa S, Lemanu DP, Connolly AB, Hill AG. Systematic review and meta-analysis of use of serum $C$ reactive protein levels to predict anastomotic leak after colorectal surgery. Br J Surg. 2014;101:339-46.

29. Bianchi R, Silva N, Natal M, Romero M. Utility of base deficit, lactic acid, microalbuminuria, and C-reactive protein in the early detection of complications in the immediate postoperative evolution. Clin Biochem. 2004;37:404-7.

30. Deitmar S, Anthoni C, Palmes D, Haier J, Senninger N, Brüwer M. Are leukocytes and CRP early indicators for anastomotic leakage after esophageal resection? Zentralbl Chir. 2009;134:83-9.

31. Ma GW, Situ DR, Ma QL, Long H, Zhang LJ, Lin P, et al. Three-field vs twofield lymph node dissection for esophageal cancer: a meta-analysis. World J Gastroenterol. 2014:20:18022-30.

32. Wang HW, Kuo KT, Wu YC, Huang BS, Hsu WH, Huang MH, et al. Surgical results of upper thoracic esophageal carcinoma. J Chin Med Assoc. 2004;67:447-57.

33. Kato $H$, Tachimori $Y$, Watanabe $H$, Yamaguchi $H$, Ishikawa $T$, Kagami $Y$. Thoracic esophageal carcinoma above the carina: a more formidable adversary? J Surg Oncol. 1997;65:28-33.

34. Biere SS, van Berge Henegouwen MI, Maas KW, Bonavina L, Rosman C, Garcia JR, et al. Minimally invasive versus open oesophagectomy for patients with oesophageal cancer: a multicentre, open-label, randomised controlled trial. Lancet. 2012;379:1887-92.

\section{Submit your next manuscript to BioMed Central and we will help you at every step:}

- We accept pre-submission inquiries

- Our selector tool helps you to find the most relevant journal

- We provide round the clock customer support

- Convenient online submission

- Thorough peer review

- Inclusion in PubMed and all major indexing services

- Maximum visibility for your research

Submit your manuscript at www.biomedcentral.com/submit
Biomed Central 